\title{
Eco-friendly Synthesis of Aliphatic Polyester using Castor oil Derivative and it's studies
}

\author{
MANDAR KARVE $^{1 *}$, ARVNABH MISHRA ${ }^{1}$ and MAYANKKUMAR MAKWANA ${ }^{1}$ \\ ${ }^{1}$ Department of Industrial Chemistry, Institute of Science \& Technology for Advanced Studies \\ \& Research (ISTAR), Vallabh Vidyanagar, Gujarat, India. \\ ${ }^{*}$ Corresponding author E-mail: drmandarkarve@gmail.com
}

http://dx.doi.org/10.13005/ojc/360334

(Received: May 12, 2020; Accepted: June 13, 2020)

\begin{abstract}
Solvent free aliphatic saturated polyester was prepared using sustainable castor oil derivative. The prepared polyester has biodegradable properties also it is low cost product. Due to one of renewable component in the polyester, it helps in environmental concern as it will not create any land pollution due to biodegradability. The objective of this article was to synthesize aliphatic polyester without addition of solvent during esterification. The solvent free reaction was optimized by using different parameter such as mole ratio, reaction time and reaction temperature. Prepared aliphatic polyester is used in degradable medical disposal material, synthetic lubricants for automobile industries. Product was analyzed using Fourier Transform Infrared Spectroscopy (FTIR), Molecular weight determination by viscometer and acid value determination at different reaction stages.
\end{abstract}

Keyword: Castor oil derivative, Aliphatic polyester, Solvent free reaction, Bio-degradable polymer.

\section{INTRODUCTION}

Accumulations of polymer waste in the environment and it's environmental problems led to an upsetting reaction among scientists around the globe. Therefore, to stop such build up in the environmental, the development of ecological polymers based on natural resources becomes an effective method ${ }^{1}$. Biodegradable polymers are called as green materials, due to their exceptional thermal and chemical resistance, biodegradability and melt processability are gaining increasing acceptance. Aliphatic polyesters with relatively good physical properties are similar to those of traditional plastics at a certain degree ${ }^{2}$.
As means of overcoming the problems which is associated with the disposal of traditional plastic materials, the use of biodegradable polymers has been demanded. Renewable resources of raw materials such as starch, cellulosic wastes, agricultural wastes, saw dust and vegetable oils had been used for the production of variety of end products. Among these, vegetable oils have advantages due to its availability, versatilities and technical feasibilities in polyester production ${ }^{3,4}$. Polyesters prepared from castor oil derivatives was saw good performance than ester produced from raw material which are based on petroleum. Polyesters are considered the most competitive biodegradable polymers commercialized till now ${ }^{5,6}$.

This is an Open Access article licensed under a Creative Commons license: Attribution 4.0 International (CC- BY). Published by Oriental Scientific Publishing Company @ 2018 
The desire to replace petroleumbased materials with environmentally friendly and sustainable alternatives has stimulated the development of castor oil-based products. The global demand for petroleum oil has grown dramatically during the past decade whereas the stock of crude oil has grown slowly. In the long run, one solution to reducing society's reliance on petroleum is to promote alternative renewable resources. Polyesters derived from aliphatic diols and aliphatic dicarboxylic acids are biodegradable materials, which represent an alternative to biodegradable polyesters derived from lactones or cyclic diesters ${ }^{7,8}$.

Esterification reaction can be realized in the absence of catalysts, it is extremely slow, because of autoprotolysis of the carboxylic acid. Catalysts such as mineral acid, p-toluene sulfonic acid and ion exchange resins are always used in liquid phase esterification reactions to raise the product yield. In the present study focused was kept on aliphatic polyester based on castor oil derivatives. Sebacic acid is one of the greatest renewable derivatives castor oil. It is saturated compound having straight chain dicarboxylic acid having 10 carbon atoms ${ }^{9,10}$. Sebacic acid is an intermediate product of $\omega$-oxidation of long-chain aliphatic acids. Compared with short-chain aliphatic acid, sebacic acid is more suitable for the preparation of polyesters, as short-chain aliphatic acids always conduce to intramolecular condensation. However works on polyesters of sebacic acid are rare ${ }^{11}$.

Present work proceed with esterification of sebacic acid with 1,2-propanediol which is also known as propylene glycol. Propylene glycol is synthetic organic compound, viscous, colourless and lightly bitter sweet in taste. The prepared polyester resin was made by solvent free method which proves economical and green pathway. The objective of this study to create alternative way for the preparation of high molecular weight aliphatic polyesters by sebacic acid based ester. Optimization parameter such as effect of mole ratio of sebacic acid to propylene glycol, reaction time, and reaction temperature and effect molecular weight was carried out.

\section{MATERIALS AND METHODS}

\section{Materials}

Sebacic acid, p-toluene sulfonic acid
(PTSA), potassium hydroxide $(\mathrm{KOH})$ were purchased from Sigma Aldrich. Propylene glycol, acetone and methanol were purchased from Merck India Private Ltd. Solvents and other chemicals were used of A.R grade and used after routine purification.

\section{Methods \\ Preparation of aliphatic polyester}

Synthesis of aliphatic polyester was carried out by esterification reaction. Reaction was carried out between sebacic acid and propylene glycol in presence of catalyst p-toluene sulfonic acid in 4 neck round bottom flask with nitrogen purging apparatus. Reaction temperature was raised slowly up to $120^{\circ} \mathrm{C}$ in 1 hours. Then temperature was raised to $150^{\circ} \mathrm{C}$. The reaction was carried out until lowest acid value was obtained. As per esterification mechanism, water was formed was been removed during reaction using simple distillation instead of dean and stark assembly.

\section{Acid value method}

Acid value of aliphatic product was determined time to time during esterification reaction. Pre-weigh sample was dissolved in acetone and titrated against standard alcoholic potassium hydroxide solution, using phenolphthalein indicator.

Acid value $=\frac{\text { B.R. X N X 56.1 }}{\text { Weight of the sample taken }}$

Where, $\mathrm{N}=$ Normality of the alcoholic $\mathrm{KOH}$ solution.

\section{Molecular weight determination}

Molecular weight product was measured by Ostwald viscometer and the data obtained by this technique is called viscosity average molecular weight.

\section{Fourier Transform Infrared spectroscopy}

The FTIR characterization was carried for aliphatic polyester using Perkin Elmer spectrum GX instrument by Nujol mull method.

\section{RESULT AND DISCUSSION}

Propylene glycol having two-OH group and sebacic acid also having the two- $\mathrm{COOH}$ group which make the linier chain type polymer and produces the water as by-product. Due to reversible reaction, removal of water from reaction mass was very essential, if the water in reaction mass was 
present then reaction will not proceed in forward direction. And it can observed from the acid value of reaction mass, which was under observation at regular interval of time by which the completion of reaction. Major esterification reaction behaviour which observed were simple reagents and condition at which reaction takes place, thermodynamically controlled the reaction as reaction moves forward it gets easy to handle, the use of strong acid can be done because no any other acid sensitive group is present. Also the production of water reflects direction of reaction stage.

Reaction condition parameters such as reaction time, mole ratio, temperature and molecular weight were optimized for synthesized product.

Table: 1 Effect of temperature

\begin{tabular}{lccc}
\hline No & Time & Temperature $\left({ }^{\circ} \mathrm{C}\right)$ & Acid value \\
\hline 1 & & & \\
& 6 hour & 140 & 53.34 \\
2 & & 150 & 12.34 \\
3 & & 160 & 47.37 \\
4 & & 170 & 92.61 \\
\hline
\end{tabular}

\section{Effect of temperature}

Effect of temperature and their relevant results on reaction was shown in Table 1. Number of experiment were carried out to get optimize temperature condition. As at $140^{\circ} \mathrm{C}$, reaction was not completed with optimize reaction time therefore unreacted reaction mass was found at end of reaction which results in higher acid value. It was found that reaction temperature should be increased such way that lower acid value product formed and unreacted mass was minimize or null. There so, by increasing temperature to $150^{\circ} \mathrm{C}, 160^{\circ} \mathrm{C}$ and $170^{\circ} \mathrm{C}$, product might met to above stated criteria. Due to physical property at higher temperature, loss of one of reactant during reaction was found which leads high acid value and some left unreacted mass at the end. At $150^{\circ} \mathrm{C}$, stable reaction temperature where it gains the low acid value with good quality of product.

Table: 2 Effect of mole ratio

\begin{tabular}{lccc}
\hline No & Mole ratio (acid: alcohol) & Temperature & Acid value \\
\hline 1 & $1.0: 1$ & & 47.37 \\
2 & $1.0: 1.1$ & $150^{\circ} \mathrm{C}$ & 34.19 \\
3 & $1.0: 1.2$ & & 12.34 \\
\hline
\end{tabular}

\section{Effect of mole ratio}

During the esterification, mole ratio of sebacic acid and propylene glycol were studied. Experimental data shown in Table 2. Mole ratio has great effect on acid value of end product. Different mole ratio stated in table were studied. Loss of propylene glycol during the reaction was the big problem as mole ratio need to be raised such way where acid value get reduced as well excess reactant were also recycled/recovered at the end using simple distillation technique. Moles of glycol was increased compared diacid gradually lower acid value was found.

Table: 3 Effect of reaction time

\begin{tabular}{lccc}
\hline No & Time(hours) & Temperature & Acid value \\
\hline 1 & 5 & & 92.41 \\
2 & 6 & $150^{\circ} \mathrm{C}$ & 12.34 \\
3 & 7 & & 11.78 \\
\hline
\end{tabular}

\section{Effect of reaction time}

Esterification of glycol with sebacic acid was carried out where effect of reaction time on acid value was studied. Respective experimental data were tabulated in Table 3 . At $5 \mathrm{~h}$ of reaction time, yield of the product was low as the reaction was not completed till time and results in unreacted mass with high acid value product at the end. While at $7 \mathrm{~h}$ of reaction time it was noticed that high acid value product was obtained with loss of glycol during esterification reaction. During $6 \mathrm{~h}$ reaction time, low acid value product was obtained comparatively. There was negligible decrease found in the acid value for $7 \mathrm{~h}$ reaction time. There so, $6 \mathrm{~h}$ reaction time was economically optimized parameter.

Table 4: Effect of acid value on molecular weight

\begin{tabular}{ccc}
\hline No. & Acid value & Molecular weight \\
\hline 1 & 29.63 & 14,328 \\
2 & 12.34 & 29,578 \\
\hline
\end{tabular}

\section{Effect on molecular weight}

Molecular weight of prepared aliphatic polyester was determine. Experimental data were shown in Table 4. As the acid value decreases the molecular weight get increase which gives the long chain polyester. Such system has good crosslinking abilities with good physical and chemical properties.

\section{FTIR}

FTIR spectra of synthesized aliphatic polyester from castor oil derivative with glycol 
was shown in Fig. 1. Spectra shows the different functional group present in end product such as ester, alcohol and acid and their peaks. Carbonyl functionality of aliphatic ester group present in sample shows the strong peak in graph where the $\mathrm{C}=\mathrm{O}$ streching observed at at $1737.67 \mathrm{~cm}^{-1}$. The strong absorption band observed at 1737.67 $\mathrm{cm}^{-1}$ which confirms formation of aliphatic ester group. The stretching at $1175.27 \mathrm{~cm}^{-1}$ confirms the presence of $\mathrm{C}-\mathrm{O}$ group. The $\mathrm{O}-\mathrm{H}$ stretching vibration at $2931.58 \mathrm{~cm}^{-1}$ confirms the presence of alcohol. Strong absorption band was observed at $1089.29 \mathrm{~cm}^{-1}$ confirms the incorporation of glycol to the synthesized aliphatic product.

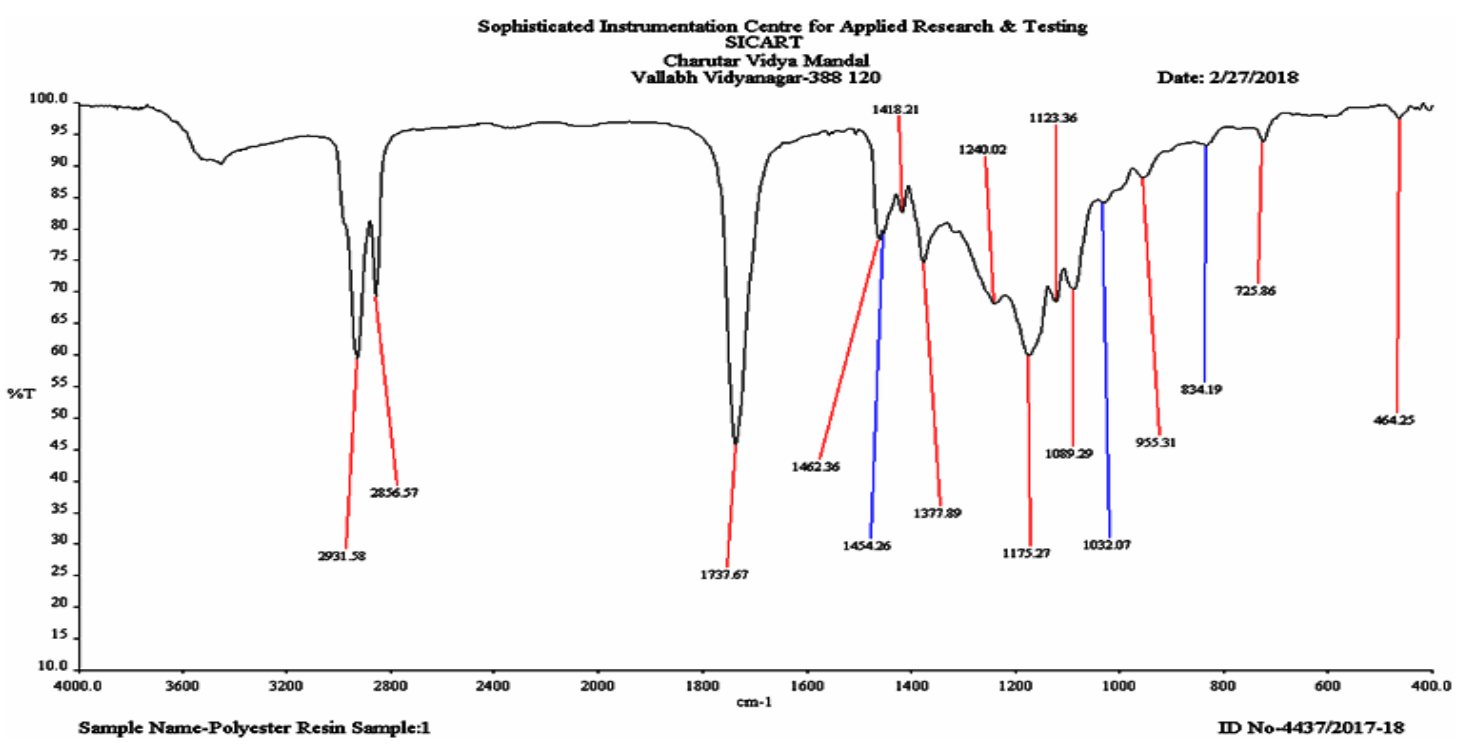

Fig. 1. FTIR spectra of ester from sebacic acid

CONCLUSION

Synthesis of aliphatic polyester from castor oil derivative with glycol was done successfully by ecofriendly method. Selection of raw material plays essential role. Aliphatic polyester was prepared with the higher molecular weight of 29,578 and acid value of 12.34 . Product may further used for biomedical application. Different reaction parameter were optimized such as reaction temperature $150^{\circ} \mathrm{C}$, mole ratio of $1.0: 1.2$ with 6 $\mathrm{h}$ of reaction time and 12.34 acid value.

\section{ACKNOWLEDGMENT}

The authors are thankful to Director, ISTAR and Head, Department of Industrial Chemistry, ISTAR, Charutar Vidyamandal University, Vallabh Vidyanagar, for providing laboratory facilities to carry out this research work.

\section{Conflict of interest}

The authors have no conflicts of interest.

\section{REFERENCE}

1. Cheng, Z.; Yang, Li. RSC Adv., 2015, 84, 7. Papageorgiou, G. Z.; Bikiaris, D.N.; Achilias 68688-68699.

2. Díaz, A.; Katsarava, R.; Puiggalí, J. Int. J. of Mole. Sci., 2014, 15, 7064-7123.

3. Billiet, L.; Fournier, D.; du Prez, F. J. Polym. Sci. A., 2008, 46, 6552-6564.

4. Karve, M.; Polara, S.; Meman, M. Int. Res. J. of Engi. Tech., 2016, 3, 513-520.

5. Karve, M.; Patel, J. J.; Sinha, V. K.; Patel, N. K. The Int. J. of Chem. Sci. Tech., 2016, 1, 28-36.

6. Baochun, G.; Zhang, L. Biomacromole., 2011, 12, 1312-1321.

D. S.; Nanaki, S.; Karagiannidis, N. J. Polym. Sci. B Polym. Phys., 2010, 48, 672-686.

8. Seyednejad, H.; Ghassemi, A. H.; van Nostrum, C. F.; Vermonden, T.; Hennink, W. E. J. Control. Re., 2011, 152, 166-176.

9. Karve, M.; Patel, J. J.; Sinha, V. K.; Patel, N. K. Environ Sci Ind J., 2015, 11, 1-7.

10. Tang, J.; Zhang, Z. S.; Zifeng, C.; Liran, H. X. Eur. Poly. J., 2006, 42, 3360-3366.

11. Sokolsky, P. M.; Langer, R.; Domb, A. J. Poly. Adv. Technol., 2011, 22, 502-511. 